\title{
Racismo Institucional: um desafio para a eqüidade no SUS?
}

\section{Institutional Racism: a challenge to equity in the National Health System (SUS)?}

\section{Suzana Kalckmann}

Pesquisadora do Instituto de Saúde da SES-SP, Doutoranda em ciências, Área de Concentração em Infectologia em Saúde Pública, Coordenadoria de Controle de Doenças, SES-SP.

Endereço: Rua Santo Antonio 590, $2^{\circ}$ Andar, Bela Vista,cepol413-000, São Paulo,SP, Brasil.

E-mail: suzanak®isaude.sp.gov.br

\section{Claudete Gomes dos Santos}

Educadora da Saúde Pública do Instituto de Saúde da SES-SP, Historiadora e Mestre em Ciências.

E-mail: cgsantosळisaude.sp.gov.br

\section{Luís Eduardo Batista}

Assistente Técnico da Coordenadoria de Controle de Doenças (CCD), Pesquisador do Instituto de Saúde da SES-SP e representante da Secretaria de Estado da Saúde de São Paulo no ConseIho de Participação e Desenvolvimento da Comunidade Negra do Estado de São Paulo, Doutor em Sociologia.

E-mail: lebatistaœsaude.sp.gov.br

\section{Vanessa Martins da Cruz}

Assistente de pesquisa do Instituto de Saúde, SES-SP, Fisioterapeuta. E-mail: vanessa®isaude.sp.gov.br

\section{Resumo}

O racismo institucional é definido como o "fracasso coletivo de uma organização para prover um serviço apropriado e profissional para as pessoas por causa de sua cor, cultura ou origem étnica. Ele pode ser visto ou detectado em processos, atitudes e comportamentos que totalizam em discriminação por preconceito involuntário, ignorância, negligência e estereotipação racista, que causa desvantagens a pessoas de minoria étnica”. A prática do racismo institucional na área da saúde afeta preponderantemente as populações negra e indígena. Este artigo tem como objetivo relatar a sondagem de opinião sobre a existência de racismo nos serviços de saúde. Para isso, foi realizado um estudo exploratório, aprovado pelo Comitê de Ética em Pesquisa do Instituto de Saúde, com análise de questionário auto-aplicável entregue aos participantes do $2^{\circ}$ Seminário de Saúde da População Negra do Estado de São Paulo, ocorrido no Município de São Paulo, em 17 de maio de 2005. Os resultados evidenciam que a população negra vem sendo discriminada nas unidades de saúde, como usuários e como profissionais. Verificou-se que os serviços de saúde, por meio de seus profissionais, aumentam a vulnerabilidade desses grupos populacionais, ampliando barreiras ao acesso, diminuindo a possibilidade de diálogo e provocando o afastamento de usuários. Diante do encontrado, acredita-se ser importante estimular discussões sobre o tema e desenvolver estudos que além de dar visibilidade às iniqüidades possam contribuir para a compreensão de como as discriminações atuam na saúde da população negra.

Palavras-chave: Racismo institucional; Saúde da população negra; Discriminação racial. 


\section{Abstract}

Institutional racism is defined as the collective failure of an organization to provide appropriate and professional services for people because of their color, culture or ethnic roots. It can be seen or detected in processes, attitudes and behaviors that produce discrimination due to unintentional prejudice, ignorance, negligence and racism stereotypes, causing dis-advantage to people belonging to ethnic minorities. The practice of institutional racism in the health area affects specially the black and indigenous populations. The present article aims to present an investigation into opinions about the existence of racism in the health services. To achieve this, an exploratory study was conducted, approved by the Committee for Research Ethics of the Health Institute (Instituto de Saúde do Estado de São Paulo), with the analysis of a self-administered survey delivered to those who attended the $2^{\text {nd }}$ Black Population Health Seminar of the state of São Paulo, which was held in the city of São Paulo on May 17, 2005. The results show that the black population has been discriminated in the health units, both as users and as professionals. It was verified that the health services, through their professionals, increase the vulnerability of those groups, enlarging access barriers, reducing the possibility of dialog and causing the withdrawal of users. In light of these findings, it is believed that it is important to stimulate discussions about the topic and develop studies to give visibility to the inequities and, therefore, contribute to the understanding of how discrimination acts in the black population's health. Keywords: Institutional Racism; Black Population's Health; Race Discrimination.

\section{Introdução}

Estudos nacionais e internacionais evidenciam que há desigualdades importantes entre a saúde de brancos e negros, homens e mulheres, explicitando interações sinérgicas entre desigualdades sociais, raciais e de gênero (Williams, 1997; Silvério, 2002, Oliveira, 2002). Não há como negar o peso da dimensão étnicoracial nos profundos problemas sociais que assolam o país, “(...) bloqueando relações, possibilidades de participação, inibindo aspirações, mutilando práxis humana, acentuando a alienação de uns e de outros, indivíduos e coletividades" (Ianni, 2004, p. 23).

A discriminação por cor/raça, na maioria das vezes de forma velada, em virtude de leis que a proíbem, perpetrada por meio de “(...) mecanismos de expressão que não ferem abertamente essas normas" (Pereira e col., 2003, p. 95), determina diferenças importantes no acesso e na assistência nas diferentes esferas da sociedade, como, por exemplo, na menor oportunidade de escolarização, “(...) na polícia e outras forças de autoridade e controle social através de prisões ilegais e detenções arbitrárias (...), na justiça, como reflexo da falta de informação e da relação melhor rendimento econômico/melhor defesa e de penas distintas, (...)" (Lopes, 2005).

Estas diferenças no âmbito dos direitos e do espaço público configuram o racismo institucional, definido como: "O fracasso coletivo de uma organização para prover um serviço apropriado e profissional para as pessoas por causa de sua cor, cultura ou origem étnica. Ele pode ser visto ou detectado em processos, atitudes e comportamentos que totalizam em discriminação por preconceito involuntário, ignorância, negligência e estereotipação racista, que causa desvantagens a pessoas de minoria étnica" (Documento da Comission for Racial Equality, 1999 apud Sampaio, 2003, p. 82).

Na área da saúde, estudos recentes têm evidenciado "que as desigualdades quanto à saúde e [à] assistência sanitária dos grupos étnicos e raciais são óbvias e que, das explicações de tais desigualdades, o racismo é a mais preocupante" (Organización Mundial de la Salud, 2001, p. 7).

As pessoas tornam-se impotentes diante de uma situação não explícita de discriminação. A sensação 
de impotência é igual ou maior do que a vivida diante da agressão física, porque as vítimas não encontram acesso a recursos e a apoios adequados para se protegerem do agravo e de suas conseqüências indesejáveis (Lopes, 2003).

A prática do racismo institucional na área da saúde afeta preponderantemente as populações negra e indígena. A invisibilidade das doenças que são mais prevalentes nestes grupos populacionais, a não inclusão da questão racial nos aparelhos de formação, a dificuldade de acesso aos serviços de saúde, a qualidade da atenção à saúde, assim como o acesso aos insumos, determinam diferenças importantes nos perfis de adoecimento e morte entre brancos e negros (Loureiro e Rozenfeld, 2005; Lopes, 2005a; Batista e col., 2005).

O racismo minimiza as possibilidades de diálogo das pessoas com os serviços, interfere na auto-estima e, conseqüentemente, contribui de forma decisiva na saúde, especialmente mental dos usuários (Silva, 2005; Lopes, 2005b). Por conseguinte, quando presente nos serviços, reforça, quando não agrava, a exclusão social.

Este trabalho tem como objetivo relatar os resultados de uma sondagem acerca da existência de racismo nos serviços de saúde.

\section{Um Pouco de História...}

No final do século XV e início do XVI, a Europa estava no seu apogeu “(...) como dona dos mares e do dinheiro e como pedestal do homem branco senhor do mundo, (...)" (Carvalho, 1984, p. 10). Imbuídos dessa ideologia, os conquistadores europeus - especificamente espanhóis e portugueses - iniciaram a colonização da América recém descoberta implementando um sistema produtivo baseado na mão-de-obra escrava (Davidoff, 1986).

Assim, populações inteiras de indígenas foram escravizadas e exterminadas (Carvalho, 1984; Sivanandan, 2002), com o beneplácito da Igreja Católica, que, comungando com o ideário da superioridade dos brancos europeus sobre os demais povos, considerava os indígenas “(...) 'sub-homens', os filhos de Cam, nascidos para ser escravos, e que podiam, por conseguinte, ser escravizados ou exterminados" (Sivanandan, 2002).
A adoção sistemática dessa prática resultou na redução da mão-de-obra escrava indígena e, para supri-la, os europeus voltaram os olhos para a África, dando início à escravidão negra, igualmente placitada pela Igreja Católica, por governantes e por intelectuais como Montesquieu, que, como diz Freitas (1985, p. 12), “(...) fundamentou na religião o racismo antinegro", ao afirmar que: "Não se pode admitir a idéia de que Deus, que é um ser infinitamente sábio, tenha colocado uma alma, sobretudo uma alma boa, em um corpo completamente negro" (Montesquieu apud Freitas, 1985, p. 12).

A África, assim, sofreu durante séculos uma espoliação sistemática, levada a efeito por traficantes de escravos e governos europeus (Carvalho, 1984). As “(...) idéias racializadas das épocas prévias se congelaram em uma ideologia racista sistêmica para condenar toda a gente de 'cor' à inferioridade racial e cultural" (Sivanandan, 2002), sendo justificada, portanto, a sua escravidão.

Em 1855, a publicação do livro Ensaio Sobre as Desigualdades Raciais, de Arthur Joseph Gobineau, começa a dar à ideologia racista uma validade "científica” (Carvalho, 1984; Sivanandan, 2002). 0 autor defendia no livro “(...) a 'superioridade' inata do 'ariano', ramo superior da raça branca, destinado a governar sobre os demais" (Carvalho, 1984, p. 10). Essa teoria encontrou eco no pensamento racista, popularizando ainda mais a questão das hierarquias sociais dos indivíduos.

\section{Enquanto Isso, no Brasil...}

No Brasil, o racismo tem suas raízes na escravidão e, por conseguinte, na "anulação dos valores da cultura negra feita pelos colonizadores como forma de legitimar a dominação" (O Negro..., 1986, p. 3). A força desse racismo pode ser medida pelo fato de a escravidão ter dominado a história do Brasil por mais de três séculos, sendo o último país do mundo a aboli-la. Como afirma Freitas (1985, p. 12), "Nenhuma outra região do Novo Mundo foi tão completamente modelada e condicionada pela escravidão quanto o Brasil. Simplesmente, a escravidão fez o Brasil”.

Não se pode afirmar, sem incorrer em erro, o número exato de africanos trazidos ao Brasil desde a segunda metade do século XVI até 1850, quando o tráfico de escravos passou a ser considerado crime, por 
meio da Lei no ${ }^{\circ} 851$ - Lei Eusébio de Queirós, de 4 de setembro de 1850 (Brasil, 2007). Diversos historiadores se debruçaram, e ainda o fazem, sobre o tema, mas o que se tem são apenas estimativas das mais diversas (Moura, 1994), nunca abaixo de 3 milhões. Para Alencastro (2006), “(...), mais de 4 milhões de africanos foram deportados para o Brasil entre 1550 e 1850 , tornando o Brasil o agregado político americano que recebeu a maior parte dos africanos desembarcados no Novo Mundo".

Apesar desses números, a situação dos negros não melhorou após o 13 de maio de 1888. Embora não havendo a lavratura de qualquer instrumento jurídicoinstitucional impondo barreiras legais aos ex-escravos, a extinção da escravatura não extinguiu o racismo no país. A Lei Áurea deu aos negros "o estatuto de pessoas juridicamente livres" (Arruda, 1995, p. 7), mas não os livrou da exclusão e da discriminação, pois a ideologia racista permaneceu, “(...) a ideologia segundo a qual o negro, homem inferior, pode e deve ser discriminado" (Freitas, 1985, p. 12).

Consonante com esse ideário, a classe dominante brasileira optou pela imigração de europeus brancos, com o claro intuito de "branquear" o país (Freitas, 1985; Rolnik, 1986; Heringer, 2002; Barreto, 2004).

Como diz Rolnik (1986, p. 3), essa opção “(...) implicou também a formulação de uma teoria social - a raça negra estava condenada pela bestialidade da escravidão - e a vinda de imigrantes europeus traria elementos étnicos superiores que, através da miscigenação, poderiam branquear o país, como 'uma transfusão de puro e oxigenado sangue de uma raça livre'. A operação substituição da mão-de-obra escrava significou, portanto, a redefinição do lugar do negro na sociedade - de escravo a marginal”.

A ideologia do "embranquecimento (branqueamento)" representou, então, "a passagem do racismo de dominação ao racismo de exclusão” (Sodré, 1995, p. 6), pois, para os detentores do poder, “(...) negro livre não servia para trabalhar. A posição de marginalidade do negro em relação a esta nova configuração social seria, então, justificada através da idéia de inferioridade cultural da raça negra, característica responsável pela 'inadaptação' dos libertos a uma relação mais moderna de trabalho" (Rolnik, 1986, p. 3).

Devido a essa "inadaptação", aos negros sobraram “as ocupações improdutivas” (Freitas, 1985, p. 13): emprego doméstico, biscates, enfim, as ocupações subalternas (Freitas, 1985; Moura, 1985). Nascia assim uma massa de miseráveis, “(...) herdeiros de tudo aquilo de negativo que os blocos de poder do Império e da República legaram como herança econômica, política, social e cultural aos escravos e ex-escravos" (Moura, 1985, p. 15).

Em linhas gerais, o desemprego, o analfabetismo, a subnutrição, a fome e a doença que assolam sobremaneira os negros, são reflexos de uma ideologia excludente que “(...) continua pesando, através do racismo ambíguo e dissimulado do brasileiro, a esmagar não apenas economicamente, mas, também, psicológica, cultural e existencialmente a grande população não-branca do Brasil. O racismo é, assim, a arma ideológica através da qual os opressores discriminam os não-brancos para manter os seus níveis de privilégio, como, antes, os senhores de escravos da mesma forma procediam" (Moura, 1985, p. 15).

Apesar de recentes leis antidiscriminatórias e da melhoria da imagem do negro, sua real condição na sociedade brasileira ainda é de desvalorização. $\mathrm{Na}$ esfera governamental, observa-se que “(...) as iniciativas de combate às desigualdades raciais ainda têm um alcance limitado e podem ser mais facilmente identificadas nos documentos e recomendações do que por meio de ações práticas” (Heringer, 2002, p. 62). Por sua vez, no âmbito social, "ainda há discrepâncias entre 'imagem e prática' a respeito da segregação e discriminação racial no nosso país, onde, freqüentemente, vemos pessoas afirmarem que o povo brasileiro está se tornando um povo mais homogêneo, mas em todo momento flagramos evidências de práticas discriminatórias na vida cotidiana” (Barreto, 2004, p. 245).

Assim, pressupõe-se que a sociedade brasileira contemporânea permanece racista e esse racismo também está presente no Estado e, conseqüentemente, nas instâncias governamentais (nos aparelhos formadores, nos serviços de atenção aos cidadãos, nas políticas públicas, dentre outros). 0 governo, ao não dar a devida visibilidade às desigualdades raciais existentes na sociedade, ao não ter uma política explicita de combate ao racismo, colabora para a sua institucionalização.

O presente artigo tem como objetivo relatar a sondagem de opinião sobre a existência de racismo nos serviços de saúde e subsidiar a discussão de racismo institucional entre os profissionais de saúde. 


\section{Metodologia}

Estudo exploratório aprovado pelo Comitê de Ética em Pesquisa do Instituto de Saúde, com análise de questionário auto-aplicável, com informações sobre as variáveis demográficas e sociais (idade, sexo, cor/raça, escolaridade, estado civil, ocupação, religião), questões sobre a percepção dos participantes acerca do racismo e relato de experiências vivenciadas, entregue aos participantes do $2^{\circ}$ Seminário de Saúde da População Negra do Estado de São Paulo, ocorrido no Município de São Paulo, em 17 de maio de 2005.

O seminário realizado anualmente é dirigido às lideranças do movimento negro, gestores e profissionais do SUS, e tem como objetivos instrumentalizalos e sensibiliza-los sobre os principais temas/problemas de saúde da população negra.

Considerando-se o registro de inscrições, 553 pessoas participaram do evento, das quais $294(53,2 \%)$ se autodefiniram de cor preta, 103 (18,6\%) de cor parda, $147(26,6 \%)$ de cor branca, 5 (0,90\%) indígena e 4 $(0,72 \%)$ de cor amarela; $285(51,5 \%)$ residiam na capital, 178 (32,2\%) no interior, 8o (14,5\%) na Grande São Paulo e 10 (1,8\%) em outros estados.

Dos questionários distribuídos, 240 (46,3\%) foram devolvidos respondidos. A análise dos dados foi feita por meio do programa EpiInfo e SPSS 8,o for Windows. As respostas às perguntas sobre percepção de discriminação racial nos serviços de saúde foram analisadas segundo o significado das mensagens (Bardin, 1977).

\section{Resultados e Discussão}

A população estudada caracterizou-se por um predomínio $(71,3 \%)$ de pessoas que se autodeclararam negras considerou-se o critério adotado pelo IBGE ${ }^{1}$ - somatório dos que se autodefinem como de cor preta $(45,8 \%) \mathrm{e}$ de cor parda (21,3\%), sendo agregados também os 4,2\% que se autodefiniram como da "população negra".

Os questionários foram respondidos majoritariamente por mulheres (66\%), a idade dos respondentes variou de 14 a 68 anos, com média de $38,5( \pm 12,81)$ e mediana de 39 anos; 77,1\% exerciam atividade remu- nerada e $9 \%$ estavam desempregados. No tocante à escolaridade, $25,8 \%$ tinham curso superior completo, e apenas 2,1\% não tinham nenhuma instrução formal.

Apesar do predomínio de participantes da religião católica $(58,8 \%)$, as demais religiões também estiveram presentes: evangélica ( $15,8 \%)$, espiritismo Kardecismo ( $9,7 \%$ ), candomblé e umbanda ( $8,1 \%$ ), e budismo $(0,4 \%)$, assim como os ateus e sem religião, $1,4 \%$ e $4,8 \%$, respectivamente. Chama a atenção a proporção de não resposta a essa questão (13\%).

No total, 43,3\% (104) responderam que já perceberam alguma discriminação racial nos serviços de saúde, $60 \%, 44,2 \%$ e $40,8 \%$, entre os de cor preta, branca e parda, respectivamente. A proporção de pessoas que relataram ter vivenciado o racismo foi muito maior que a encontrada na pesquisa feita pela Fundação Perseu Abramo (2004), realizada com a população em geral. Essa pesquisa constatou que o setor saúde é o principal local discriminador, pois $3 \%$ dos entrevistados relataram ter sofrido discriminação ao buscar cuidados de saúde ( $1 \%$ brancos, $3 \%$ pardos, $6 \%$ pretos e $3 \%$ indígenas).

Não se pode deixar de considerar que a amostra do presente estudo é diferenciada comparada à população, em termos de escolaridade e de consciência/ sensibilidade diante da questão.

A partir da leitura dos relatos de racismo vivenciados, diretamente ou por meio de algum conhecido, e levando-se em conta o conceito de vulnerabilidade (Ayres e col., 1999; Lopes, 2003) foram criadas as seguintes categorias para a análise: restrição ao acesso e/ou ao atendimento (4o pessoas), qualidade do atendimento ao pré-natal e ao parto (14) restrição ao acesso e qualidade do atendimento específico a anemia falciforme (12), e relacionado às relações entre os profissionais de saúde (10). No total, 28 pessoas afirmaram ter vivenciado situação de discriminação na saúde, mas não relataram o acontecido.

Para maior detalhamento, buscou-se identificar os sujeitos envolvidos nos relatos, e para tanto, criou-se as seguintes categorias: "leu e/ou escutou sobre pesquisas", aconteceu "com a própria pessoa”, aconteceu “com parentes ou amigos”, "não-especificado".

1 Consideramos como população negra o somatório dos indivíduos que se consideram de cor preta e de cor parda, conforme categorias adotadas pelo Instituto Brasileiro de Geografia e Estatística - IBGE (Portaria nº.3947/GM. Diário Oficial da União, 1999 (www.ibge.gov.br) 
Foram mais freqüentes os episódios vividos pela própria pessoa, como profissional ou como usuário, $37 \%$ (39) do total, proporção que passa a 41,8\% (28) quando se considera os que se declaram de cor preta. Entre os relatos vividos pela própria pessoa, verificase que a cor é uma variável que interfere na intensidade com que o racismo é percebido. Resultado similar ao observado por Oliveira e Barreto (2003), ou seja, há mais relatos de pessoas que se autodefinem como de "cor preta" do que entre os que se dizem da "cor parda".

As falas apresentadas são fragmentos de histórias vividas, ou melhor, sofridas e devem ser entendidas como a materialização do racismo institucional. A análise destas situações deve ser vista como alternativa para o enfrentamento do problema, contribuindo com elementos para que os profissionais de saúde possam refletir sobre a própria prática.

\section{Restrição do Acesso aos Serviços e Atendimentos à Saúde}

Nesta categoria foram reunidos os relatos que descrevem formas diversificadas de afastar o usuário dos serviços de saúde, em diferentes tipos de atendimento.

A análise de situações percebidas como discriminatórias revela que as atitudes parecem estar ligadas à ideologia do dominador que perpassa o cotidiano estando introjetada nos profissionais, como, por exemplo, acreditar que as pessoas negras são "mais fortes e resistentes à dor", como: "Negro não adoece" (51 anos, auxiliar de enfermagem, preta); "Não é uma coisa assim fácil de falar, sinto que somos tratados com mais displicência" (51 anos, jornalista, cor preta); "Eu estava com muita dor e a médica falava: que é isso? Não dói tanto" (23 anos, professora, parda); "Rapaz! Um negão desse tamanho sentindo dor?" (55 anos, agente comunitário de saúde, cor preta); "Médicos atendem de forma diferente infratores negros e brancos" (37 anos, agente educacional da Febem, cor preta).

Há uma tendência a minimizar as queixas.

"A discriminação está presente em todos os setores da vida brasileira” (28 anos, psicólogo, cor parda); "Na rotina dos nossos serviços, é muito comum a utilização de palavras discriminatórias, que afastam as pessoas" (36 anos, enfermeira, cor branca).

Em várias situações são usadas palavras, ou melhor, insultos, que, segundo Guimarães (200o), têm a função de manter as relações estabelecidas historica- mente. Para o autor, esses insultos são mensagens para que o cidadão negro não se esqueça de seu lugar subalterno nas relações e retorne ao seu lugar inferior. É interessante refletir sobre o significado que palavras como "negão", "negro", "preto”, "roxinho”, etc., assumem, especialmente, quando acompanhadas de atitudes como as descritas, elas trazem o passado de humilhação e subordinação, falam mais que de uma simples cor.

Outras situações mostram como se dá o impedimento ao acesso e ao atendimento com eqüidade, revelam formas de acirramento das desigualdades:

"No Hospital X o médico me destratou e disse que preto tem que morrer em casa" (54 anos, cabeleireira, cor preta); "Comigo, a GO (ginecologista) não quis me examinar, eu disse que estava com corrimento e coceira" (48 anos, desempregada, cor preta).

"O meu tio foi vítima de assalto, chegou baleado no PS e foi tratado como assaltante" (55 anos, auxiliar de enfermagem, cor preta); "A enfermeira se negou a examinar minha sobrinha" (24 anos, atendente de lanchonete, cor preta); "A população quilombola não tem acesso aos serviços públicos de saúde" (4o anos, psicólogo, cor preta); "Vi uma senhora, ao não concordar ou entender a prescrição, ouvir do médico: a senhora é uma velha negra e sem diploma, eu que estudei, sei o que estou fazendo" (52 anos, presidente de ONG, cor preta).

"No Hospital X, a médica nem examinou a minha filha, passou um remédio para sarna, ela nem me ouviu falando que eu achava difícil, ela não tem contato com animal; levei a outro médico e ele descobriu um processo alérgico" (30 anos, enfermeira, cor preta).

A maioria dos relatos envolve o médico, mas os outros profissionais, como enfermeiro, psicólogo, auxiliar de enfermagem e recepcionista, também, foram citados.

Associar a cor da pele ao baixo poder aquisitivo, naturalizando o processo, parece ser uma constante: "A recepcionista demorou para me dar atenção e quando eu entreguei o cartão do convênio, ela olhou duas vezes para mim, pediu o meu RG, coisa que não havia feito com outras pacientes brancas, ela parecia não acreditar que eu pudesse pagar o convênio. Nos tratam como um ser de segunda categoria, até mesmo a solicitação do documento de identidade, pode ser interpretado como 'tirar a prova real', será que essa pes- 
soa realmente é beneficiária deste plano?" (32 anos, enfermeira, cor preta).

Vale salientar que os relatos não se restringem aos serviços públicos de saúde, incluem também renomados planos de saúde.

Não se pode deixar de considerar/refletir que atitudes como as relatadas pelos participantes, além de afastar os usuários dos serviços, interferem de forma negativa na construção de suas identidades.

\section{Qualidade do Atendimento ao Pré-Natal e Parto}

Os relatos mostram que as situações de discriminação são mais freqüentes quando as pessoas estão mais fragilizadas, como durante a gravidez e durante o parto: "Escutei a recepcionista (pré-natal) falar: negra é como coelho, só dá cria" (43 anos, diretora de ONG, cor preta); "No parto do meu último filho não me deram anestesia" (43 anos, auxiliar administrativa, negra); "O médico nem examinou a gestante negra" (40 anos, coordenador de conselho de cultura, negro); "No pré-natal, só mandavam emagrecer eu nem sabia o que era eclampsia, quase morri" (28 anos, professora primária, cor preta).

Essas falas são compatíveis às encontradas por Leal e col. (2005), que revelam que as pretas e pardas recebem pior assistência ao parto e no pré-natal nas maternidades do Rio de Janeiro. As autoras concluem que as mulheres negras peregrinam mais em busca de local para o parto, têm pior pré-natal e proporções maiores delas não recebem anestesia.

\section{Qualidade do Atendimento à Anemia Falciforme}

A anemia falciforme é a doença hereditária mais comum do Brasil, considerando a população geral, com maior prevalência entre os afro-descendentes, é causada por uma mutação do gene da hemoglobina que determina a alteração da forma dos glóbulos vermelhos, que se tornam parecidos a uma foice. As hemáceas agregam-se e dificultam a circulação do sangue nos pequenos vasos do corpo. Com a diminuição da circulação ocorrem lesões nos órgãos atingidos, podendo causar dor, inchaço, insuficiência renal, hepática, pulmonar, cerebral, priapismo, dor de cabeça, convulsões, derrame, desmaios, etc. Provoca grande variabilidade clínica, alguns pacientes têm um quadro de grande gravidade e estão sujeitos a inúmeras complicações e freqüentes hospitalizações, outros apresentam uma evolução mais benigna (Zago, 2001).
"Quando um paciente negro chega ao hospital com crise de dor por anemia falciforme, é tratado como viciado em 'dolantina' e 'franol'” (20 anos, presidente de ONG, negra);"Os médicos sabem pouco ou desconhecem a anemia falciforme" (52 anos, médico, branco); "O meu menino tinha dor no braço e eles engessaram" (48 anos, socióloga, branca ); "Eu sentia um cansaço, e me sentia culpada por não dar conta dos serviços de casa, eu estava quase acreditando que era preguiçosa, daí no pré-natal descobriram que eu tinha uma alteração nos glóbulos vermelhos" (34 anos, professora, parda ); "A gente vê muitos casos de anemia falciforme que não recebem tratamento específico" (42 anos, diretora de Escola de Samba, cor não declarada); "Quando a gente fala que é falciforme, eles olham para gente, não acreditam" (52 anos, assistente social, negra).

Segundo estimativas da OMS, nascem, anualmente, no Brasil, 2500 crianças com a patologia, das quais $20 \%$ morrem antes dos 5 anos de idade por complicações relacionadas a ela, por não ser um tema de domínio dos profissionais de saúde, há dificuldades para o diagnóstico adequado, o que contribui para o sub-registro dos óbitos causados por ela (Anvisa, 2005).

As falas indicam a persistência da situação mostrada pelo estudo clínico, que ouvindo 80 pacientes, identificou que para 9o\% deles o diagnóstico só aconteceu quando tiveram acesso a algum setor do Hospital das Clínicas da Unicamp, pois até então tiveram apenas tratamento sintomático (Silva e col., 1993).

Os relatos também denunciam a inexistência de serviços que possam atender a população, resultando em peregrinação em busca de resolução, levando ao diagnóstico tardio que, segundo os especialistas, é o maior problema para o controle da patologia.

$O$ desconhecimento dos procedimentos adequados para controlar as crises de dor e demais sinais e sintomas da doença contribui para o afastamento do paciente dos serviços de saúde, além de impingir sofrimentos que poderiam ser evitados. Isso sem considerar as mortes advindas da doença, pois, estima-se que muitos morrem sem diagnóstico.

O priapismo, que é um estado de ereção dolorosa, causada pela obstrução dos vasos do pênis, e que geralmente ocorre espontaneamente, é confundido com excitação sexual, o que encontra respaldo nos estereótipos veiculados na mídia: o homem negro sempre disposto a ter relações sexuais e a não trabalhar. 
"Meu filho sofria de priapismo, e quando era adolescente, a enfermeira me disse que ele era 'um neguinho safado”' (48 anos, psicóloga, branca).

\section{Relações entre os Profissionais de Saúde}

Apesar de em menor número, os relatos também apontam situações de racismo institucional que ocorrem entre os dirigentes e o trabalhador, entre os trabalhadores e entre usuários e trabalhadores negros.

"Muitos não são admitidos por que são negros" (6o anos, técnico químico, negro);"Os cargos de direção e de alto escalão são preenchidos por pessoas brancas" (48 anos, coordenador de cursos, pardo); "A médica branca me destratou e fez alusão a minha cor" (50 anos, psicóloga, negra); "Meu marido é médico, foi questionado se tinha competência" (46 anos, professora, negra); "A usuária não quis que auxiliar de enfermagem negra aplicasse vacina em seus filhos" (52 anos, educadora de saúde, parda).

\section{Conclusão}

Os resultados evidenciam que a população negra vem sendo discriminada nos serviços de saúde, tanto como usuários, quanto como profissionais. Embora os relatos, na sua maioria, remetam a serviços públicos, os planos privados também foram citados.

Lembrando que um dos princípios básicos do SUS é a eqüidade, ou seja, os serviços de saúde devem oferecer tratamentos diferenciados e específicos para os desiguais, visando reduzir diferenças de vulnerabilidade das populações. No caso da população negra, que é mais vulnerável a várias patologias pelo processo histórico de exclusão social, econômica, política e cultural a que foi submetida, cabe aos serviços de saúde garantir atendimentos adequados, que reduziriam essa vulnerabilidade. No entanto, verificou-se que os serviços de saúde, por meio de seus profissionais, aumentam a vulnerabilidade destes grupos populacionais, ampliando barreiras ao acesso, diminuindo a possibilidade de diálogo e provocando o afastamento de usuários.

No caso específico da anemia falciforme, patologia genética de maior prevalência entre a população negra, a sua invisibilidade nos serviços de saúde, a ausência de informação sobre ela nos aparelhos formadores (universidades), a falta de informação/formação específica para os profissionais, inclusive nos Pólos de capacitação e a inexistência de programas de atenção aos portadores é a expressão material do racismo institucional.

Os relatos das situações de discriminação apresentados, casos reais, apesar de partirem de uma amostra de conveniência do município de São Paulo, podem contribuir para que os profissionais reflitam sobre as próprias atitudes e práticas. Não se pode deixar de considerar que o racismo se evidencia nas interações entre pessoas, e que mesmo o profissional não considerando que teve uma atitude racista, ao não escutar a percepção do sujeito que sofreu a ação, está contribuindo também com o racismo institucional. Além disto, as instituições, ao não terem um posicionamento explícito e espaços onde essas condutas sejam discutidas, são coniventes e institucionalizam o racismo.

A inexistência da discussão sobre o impacto do racismo na saúde e nos aparelhos de formação, dentre eles nos cursos oferecidos pelos Pólos de Educação Permanente para profissionais médicos, enfermeiros e dentistas, reforçam o racismo na saúde.

Por fim, sejam usuários, sejam profissionais, não se pode negar que a vivência da discriminação racial interfere sobremaneira na construção das identidades e na produção dos sujeitos, e conseqüentemente na saúde das pessoas. Assim, é importante que os efeitos sociais do racismo sejam relatados para que as instituições adotem medidas para a sua desconstrução, se não na sociedade como um todo, pelo menos nas suas dependências.

Para tanto, faz-se necessário estimular discussões sobre o tema e desenvolver estudos que, além de dar visibilidade às iniqüidades, possam contribuir para a compreensão de como as discriminações atuam sobre a saúde da população negra. Além de ser fundamental que, considerando a dimensão territorial e a diversidade étnico-racial do Brasil, se promovam estudos no país, buscando identificar diferenças regionais. 0 racismo institucional deve ser aferido para que seja entendido como indicador da qualidade do atendimento prestado à população.

Espera-se que os resultados contidos neste artigo possam servir de subsídios para outros estudos que se proponham a investigar o impacto do racismo na saúde, bem como para a adoção, por parte dos poderes constituídos, de medidas efetivas para a redução das iniqüidades raciais e, especificamente, para a promoção de políticas realmente eqüitativas no âmbito do Sistema Único de Saúde. 


\section{Referências}

ALENCASTRO, L. F. As populações africanas no Brasil. Texto redigido para o capítulo relativo às 'Populações africanas no Brasil', que integrou o 'Plano Nacional de Cultura', apresentado ao Congresso em 15/12/2006 pelo ministro da Cultura, Gilberto Gil. Disponível em: <http://www.funag.gov. br/ii-conferencia-nacional-de-politica-externa-epolitica-internacional/Luiz\%20F\%20Alencastro\%20\%20As\%20\%20Populacoes\%2oAfricanas\%20no\%20Brasil. pdf/view>. Acesso em: 18 jan. 2007.

ANVISA - AGÊNCIA NACIONAL DE VIGILÂNCIA SANITÁRIA. Doença falciforme: manual do agente de saúde. Disponível em: <http://www.anvisa.gov.br/ profissional/sangue/falciforme_agente.htm>. Acesso em: 15 mar. 2006.

ARRUDA, M. A. N. Assimilação marginal ao mundo do trabalho livre. Folha de São Paulo, São Paulo, 19 mar. 1995. Mais!, p. 7.

AYRES, J. R. C. M. et al. Vulnerabilidade e prevenção em tempos de Aids. In: BARBOSA, R. M.; PARKER, R. (Org.). Sexualidades pelo avesso: direitos, identidades e poder. Rio de Janeiro: IMS: UERJ; São Paulo: Ed. 34, 1999. p. 49-72.

BARDIN, L. Análise de conteúdo. Lisboa: Ed. 7o, 1997.

BARRETO, J. H. S. Diferenças raciais e a sua relação com a saúde. Revista Baiana de Saúde Pública, Salvador, v. 28, n. 2, p. 242-258, 2004.

BATISTA, L. E. et al. Mortalidade da população negra adulta no Brasil. In: BRASIL. Fundação Nacional de Saúde. Saúde da população negra no Brasil: contribuições para a promoção da eqüidade. Brasília, DF: Funasa, 2005. p. 237-314.

BRASIL. Ministério Público Federal. Lei n 581, de 4 de setembro de 1850 - Lei Eusébio de Queirós. Estabelece medidas para a repressão do tráfico de africanos neste Império. Disponível em: <http:// www.prrı.mpf.gov.br/nucleos/nucleo_criminal/ trabalho_escravo_indigena/doutrina/trabalho_ escravo/legislacao/lei_581_4_set_1850_lei_ eusebio_de_queiros.htm>. Acesso em: 16 mar. 2007.

CARVALHO, F. M. O delírio racista. Folha de São Paulo, São Paulo, 23 dez. 1984. Folhetim, n. 414, p. 10-11.
DAVIDOFF, C. Bandeirantismo: verso e reverso. 4. ed. São Paulo: Brasiliense, 1986. (Coleção Tudo é História, 47).

FREITAS, D. Raízes históricas do racismo brasileiro. D.O. Leitura, São Paulo, v. 4, n. 42, 1985, p. 12-13.

FUNDAÇÃO PERSEU ABRAMO. Discriminação racial e preconceito de cor no Brasil. Disponível em: <http:// www.fpa.org.br/nop/racismo/index.htm>. Acesso em: 17 abr. 2006.

GUIMARÃES, A. S. A. O insulto racial: as ofensas verbais registradas em queixas de discriminação. Estudos Afro-Asiáticos, Rio de Janeiro, n. 38, p. 3148, 2000.

HERINGER, R. Desigualdades raciais no Brasil: síntese de indicadores e desafios no campo das políticas públicas. Cadernos de Saúde Pública, Rio de Janeiro, v. 18, p. 57-65, 2002. Suplemento.

IANNI, O. Dialética das relações raciais. Estudos Avançados, São Paulo, v. 18, n. 5o, p. 21-30, 2004.

LEAL, M. C.; GAMA, S. G. N.; CUNHA, C. B. Desigualdades raciais, sociodemográficas e na assistência ao pré-natal e ao parto, 1999-2001. Revista de Saúde Pública, São Paulo, v. 39, n. 1, p. 100-107, fev. 2005.

LOPES, F. Raça, saúde e vulnerabilidades. Boletim do Instituto de Saúde, n. 31, p. 7-11, dez. 2003.

LOPES, F. Experiências desiguais ao nascer, viver, adoecer e morrer: tópicos em saúde da população negra. In: BATISTA, L. E.; KALCKMANN, S. (Org.). Seminário saúde da população negra estado de São Paulo, 2004. São Paulo: Instituto de Saúde, 2005a. p. 53-101. (Temas em Saúde Coletiva, 3).

LOPES, F. Para além da barreira dos números: desigualdades raciais e saúde. Cadernos de Saúde Pública, Rio de Janeiro, v. 21, n. 5, p. 1596-16o1, set./ out. 2005 b.

LOPES, P. O lugar do 'outro' nos discurso e ação racistas. Disponível em: <http://pubol.ipbeja.pt/ Artigos/Artigo\%2oRacismo\%2oII\%2oLer\% 2oESEB.pdf >. Acesso em: 10 ago. 2005. 
LOUREIRO, M. M.; ROZENFELD, S. Epidemiologia de internações por doença falciforme no Brasil. Revista de Saúde Pública, São Paulo, v. 39, n. 6, p. 943-949, dez. 2005.

MOURA, C. Sobrevivências do sistema escravista na estrutura da sociedade brasileira. D.O. Leitura, São Paulo, v. 4, n. 42, 1985, p. 14-15.

MOURA, C. História do negro brasileiro. São Paulo: Ática, 1994.

OLIVEIRA, C. L. P.; BARRETO, P. C. S. Percepção do racismo no Rio de Janeiro. Estudos Afro-Asiáticos, Rio de Janeiro, v. 25, n. 2, p. 183-213, 2003.

OLIVEIRA, F. Saúde da população negra: Brasil ano 2001. Brasília, DF: Organização Pan-Americana da Saúde, 2002.

O NEGRO faz parte da história! Jornal do Conselho da Comunidade Negra, São Paulo, ano II, n. 4, p. 3 , jan. 1986.

ORGANIZACIÓN MUNDIAL DE LA SALUD. Saludy ausencia de discriminación. Ginebra, 2001.

Documento de la OMS para la Conferencia Mundial Contra el Racismo, la Discriminación Racial, la Xenofobia y las Formas Conexas de Intolerancia. (Serie de publicaciones sobre salud y derechos humanos, 2).

PEREIRA, C.; TORRES, A. R. R.; ALMEIDA, S. T. Um estudo do preconceito na perspectiva das representações sociais: análise da influência de um discurso justificador da discriminação no preconceito racial. Psicologia: Reflexão e Crítica, Porto Alegre, v. 16, n. 1, p. 95-107, 2003.

ROLNIK, R. Territórios negros em São Paulo. Folha de São Paulo, São Paulo, 28 set. 1986. Folhetim, n. 503, p. 2-4.
SAMPAIO, E. O. Racismo institucional:

desenvolvimento social e políticas públicas de caráter afirmativo no Brasil. Interações - Revista Internacional de Desenvolvimento Local, Campo Grande, v. 4, n. 6, p. 77-83, mar. 2003. Disponível em: <http://www.desenvolvimentolocal.ucdb.br/Revista Interacoes6_elias_oliveira_pdf $>$. Acesso em: 8 ago. 2005 .

SILVA, R. B. P; RAMALHO, A. S.; CASSORLA, R. M. S. A anemia falciforme como problema de saúde pública no Brasil. Revista de Saúde Pública, São Paulo, v. 27, n.1, p. 54-58, fev. 1993.

SILVA, M. L. Racismo e os efeitos na saúde mental. In: BATISTA, L. E.; KALCKMANN, S. (Org.). Seminário saúde da população negra estado de São Paulo, 2004. São Paulo: Instituto de Saúde, 2005. p. 129-132. (Temas em Saúde Coletiva, 3).

SILVÉRIO, V. R. Ação afirmativa e o combate ao racismo institucional no Brasil. Cadernos de Pesquisa, São Paulo, n. 117, p. 219-246, nov. 2002. SIVANANDAN, A. Los pobres son los nuevos negros. La Fogata Digital, Buenos Aires, sep. 2002. Disponível em: <http://www.lafogata.org/ozinter/og internacional/pobres.htm>. Acesso em: 10 ago. 2005. SODRÉ, M. Uma genealogia das imagens do racismo. Folha de São Paulo, São Paulo, 19 mar. 1995. Mais!, p. 6.

WILLIAMS, D. R. Race and health: basic questions, emerging directions. Annals of Epidemiology, New York, v. 7, n. 5, p. 322-333, July 1997.

ZAGO, M. A. Anemia falciforme e doenças falciformes. In: BRASIL. Ministério da Saúde. Secretaria de Políticas de Saúde. Manual de doenças mais importantes, por razões étnicas, na população brasileira afro-descendente. Brasília, DF, 2001. (Série A - Normas e Manuais Técnicos, 123). Disponível em: $<$ http://dtr2ool.saude.gov.br/bvs/publicacoes/ doencas_etnicas.pdf $>$. Acesso em: 21 nov. 2005.

Recebido em: 30/05/2006 